\section{OPEN ACCESS}

Edited by:

Jawad Kirmani,

JFK Medical Center, United States

Reviewed by:

Sonal Mehta,

University of South Carolina,

United States

Andreas R. Luft,

University of Zurich, Switzerland

${ }^{*}$ Correspondence:

Hongbing Zhang

hongbing0626@sina.com;

Aihua Liu

liuaihuadoctor@163.com

tThese authors have contributed equally to this work.

Specialty section: This article was submitted

to Endovascular and

Interventional Neurology,

a section of the journal

Frontiers in Neurology

Received: 23 April 2017

Accepted: 15 August 2017 Published: 01 September 2017

Citation:

Kang $H$, Feng $X$, Zhang $B$, Guo $E$ Wang L, Qian Z, Liu P, Wen X, Xu W,

$L i Y$, Jiang $C$, Wu Z, Zhang $H$ and Liu A (2017) The Siesta Habit is Associated with a Decreased Risk

of Rupture of Intracranial

Aneurysms.

Front. Neurol. 8:451.

doi: 10.3389/fneur.2017.00451

\title{
The Siesta Habit is Associated with a Decreased Risk of Rupture of Intracranial Aneurysms
}

\begin{abstract}
Huibin Kang ${ }^{1 \dagger}$, Xin Feng ${ }^{2,3+}$, Baorui Zhang 2,3, Erkang Guo 2,3 , Luyao Wang ${ }^{2,3}$, Zenghui Qiann ${ }^{2,3}$, Peng Liu' ${ }^{2,3}$, Xiaolong Wen ${ }^{2,3}$, Wenjuan $\mathrm{Xu}^{2,3}$, Youxiang $\mathrm{Li}^{2,3}$, Chuhan Jiang ${ }^{2,3}$, Zhongxue Wu ${ }^{2,3}$, Hongbing Zhang ${ }^{1 *}$ and Aihua Liu ${ }^{2,3 *}$
\end{abstract}

${ }^{1}$ Department of Neurosurgery, Beijing Luhe Hospital, Capital Medical University, Beijing, China, ${ }^{2}$ Department of Interventional Neuroradiology, Beijing Neurosurgical Institute, Capital Medical University, Beijing, China, ${ }^{3}$ Department of Interventional Neuroradiology, Beijing Tiantan Hospital, Capital Medical University, Beijing, China

Background: Previous studies have examined an association between the siesta habit and hypertension, as well as coronary heart disease. However, the relationship between a siesta and the risk of rupture of an intracranial aneurysm (IA) has not yet been established. We aimed to investigate the effects of a siesta on the risk of rupture of IAs.

Methods: We prospectively enrolled consecutive patients diagnosed with IAs at our hospital between January 2016 and December 2016. Univariate and multivariate logistic regression analysis were performed to identify independent risk factors associated with IA rupture.

Results: We studied 581 consecutive patients with 514 unruptured and 120 ruptured aneurysms. Univariate analysis demonstrated that hypertension, hyperlipidemia, diabetes mellitus, cigarette smoking, location, size, as well as shape and aspect ratio were associated with the risk of rupture of IAs. Multivariate analysis identified hypertension [odds ratio (OR) 1.68, 95\% confidence interval (CI) 1.03-2.73], hyperlipidemia (OR $0.25,95 \% \mathrm{Cl} 0.08-0.72$ ), current cigarette smoking $\geq 20$ cigarettes/ day (d) (OR 3.48, 95\% Cl 1.63-7.47), siesta (siesta time <1 h, OR 0.49, 95\% Cl $0.24-0.98$ and siesta time $\geq 1 \mathrm{~h}, \mathrm{OR} 0.32,95 \% \mathrm{Cl} 0.19-0.57$ ), location of largest aneurysm on the anterior communicating and internal carotid-posterior communicating artery (PCOM) (anterior communicating artery OR 16.27, 95\% Cl 7.40-35.79 and PCOM OR 11.21, 95\% Cl 5.15-24.43), and size of aneurysm $\geq 7 \mathrm{~mm}$ (OR $2.19,95 \% \mathrm{Cl} 1.21-3.97)$ as independent strong risk factors associated with risk of aneurysm rupture.

Conclusion: In the present study, we found that a habitual siesta is a new predictive factor to assess the risk of rupture of an IA. We found the siesta habit may reduce the risk of aneurysm rupture. We also found that hypertension, hyperlipidemia, cigarette smoking, location, and size of aneurysm were associated with the risk of rupture of IAs.

Keywords: siesta, intracranial aneurysm, rupture, risk factor, assessment, confidence intervals 


\section{INTRODUCTION}

While unruptured intracranial aneurysms (IAs) are found in $3-8 \%$ of the general population (1-3), only a few IAs are known to rupture (4). Approximately $2 \%$ of unruptured IAs present with subarachnoid hemorrhage (SAH) (4), which often results in death. Widespread use of neuroimaging techniques has led to detection of a greater number of incidental aneurysms (5). Although previous studies have identified demographic characteristics (viz., hypertension, smoking) and aneurysmal characteristics (viz., location, size) as independent risk factors associated with the risk of aneurysm rupture (6-12), predicting the risk of IA rupture remains controversial (13). Systemic hypertension has long been considered a significant risk factor linked to aneurysmal rupture $(14,15)$.

Particularly popular among older Chinese adults, a siesta is regarded a healthy habit. Appropriate napping can reduce systolic blood pressure, as well as decrease prevalence of hypertension in older adults (16). Previous studies have examined an association between the siesta habit and coronary heart disease and subclinical atherosclerosis $(17,18)$. However, to date, the relationship between the siesta habit and IA rupture has not been investigated. We aimed to identify the effects of the siesta habit on the risk of rupture of IA and other potential independent risk factors associated with IA rupture.

\section{MATERIALS AND METHODS}

\section{Ethics Statement}

This study was carried out in accordance with the recommendations of the Institutional Review Board of Beijing Tiantan Hospital with written informed consent from all subjects. All subjects gave written informed consent in accordance with the Declaration of Helsinki.

\section{Patient Selection}

An uninterrupted clinical database that had been developed at our hospital between January 2016 and December 2016 was reviewed retrospectively to identify all 581 patients with aneurysms (Table S1 in Supplementary Material).

Our exclusion criteria were: (1) fusiform, dissecting, traumatic, mycotic, or partially thrombosed aneurysms. (2) Intracranial hemorrhage of unknown cause, or aneurysms without clear and readable three-dimensional rotational angiography. (3) Aneurysms associated with cerebral arteriovenous fistulas, arteriovenous malformations, or moyamoya disease. (4) Patients who did not consent to participate in the study.

\section{Data Collection and Definitions}

A semi-structured telephone survey conducted by trained interviewers was used to collect data pertaining to lifestyle including the siesta habit, duration of nocturnal sleep, smoking status, and alcohol consumption status. Other baseline data were obtained from the medical history recorded by treating physicians during interviews with patients and/or family members. Aneurysmal characteristics were obtained using three-dimensional rotational angiography and evaluated by two experienced neurosurgeons.
This study examined information regarding smoking, alcohol use, height, and body weight, the incidence of hypertension, hypercholesterolemia, diabetes mellitus, ischemic stroke, and heart disease, the time of siesta and nocturnal sleep. Smoking status was classified into four groups: (1) never a smoker, (2) former smoker (quit smoking before treatment), (3) current smoker (currently smoking $\geq 20$ cigarettes/day), (4) current severe smoker (currently smoking $\geq 20$ cigarettes/day). Alcohol consumption was defined as $\geq 18 \mathrm{U}$ (viz., $\geq 150 \mathrm{~g}$ ) per week (19). Height was measured in all subjects without shoes using a tape measure to the nearest $0.1 \mathrm{~cm}$. Fasting body weight was measured in all subjects in light indoor clothing without shoes. The body mass index $\left(\mathrm{kg} \mathrm{m}^{-2}\right)$ was calculated as weight $(\mathrm{kg})$ divided by height in square meters $\left(\mathrm{m}^{2}\right)(16)$. A patient was considered hypertensive if he/she related history of using antihypertensive medications or history of unstable and untreated hypertension with systolic blood pressure $\geq 140 \mathrm{mmHg}$ or diastolic blood pressure $\geq 90 \mathrm{mmHg}$. Patients treated with antihyperlipidemic agents or with a total cholesterol level $\geq 220 \mathrm{mg} / \mathrm{dL}$ were considered as having hypercholesterolemia. A patient was considered as having diabetes mellitus if he/she had history of using antidiabetic agents or insulin injections. A participant was considered as having heart disease if he/she had history of a myocardial infarction, angina pectoris, coronary arterial bypass grafting, or percutaneous transluminal coronary arterioplasty (20). Siesta was classified as those who did not take a siesta/nap (reference), short $(<1 \mathrm{~h})$ and long $(\geq 1 \mathrm{~h})$ per day over at least 3 days a week including weekdays and weekends (16). Nocturnal sleep was classified as short ( $<6 \mathrm{~h}$, reference), medium $(6-7 \mathrm{~h})$ and long $(\geq 7 \mathrm{~h})$ per day. All participants underwent conventional digital subtraction angiography imaging to include the bilateral internal carotid arteries, bilateral external carotid arteries, and bilateral vertebral arteries for assessment of location, maximal size, and number of aneurysms.

\section{Definition of Parameters and Measurement}

Aspect ratio (AR) was defined as the ratio of the maximum perpendicular height to the average neck diameter of the aneurysm. The average neck diameter was calculated as twice the distance from the neck centroid to the edge of the neck $(21,22)$. Size ratio (SR) was defined as the ratio of maximum aneurysm height to average diameter of parent artery (23).

\section{Statistical Analyses}

The Statistical Package for the Social Sciences (SPSS, version 22.0, Chicago, IL, USA) was used to analyze the association between clinical and aneurysmal characteristics and rupture risk. A twosided $P$ values $<0.05$ was considered as statistically significant. Variables were reported as mean $\pm S D$, and examined by student's $t$-tests. Categorical variables were analyzed using Pearson's $\chi^{2}$ tests. Pearson chi-square test or Fisher's exact test were used to evaluate categorical variables. Variables that were not normally distributed were analyzed using the Mann-Whitney $U$-test. As predetermined, variables with a $P$ value of $<0.05$ in the univariate logistic regression analysis were evaluated in the multivariate 
analysis. Multivariate logistic regression analysis (forward stepwise conditional) was performed to identify independent risk factors associated with IA rupture.

\section{RESULTS}

Our study included 581 consecutive patients with 634 IAs, including 120 ruptured and 514 unruptured IAs. These patients included 219 men and 362 women. The mean age was $53.4 \pm 10.9$ years. Baseline demographic characteristics of patients are shown in Table 1. IAs were divided into a ruptured and unruptured group based on findings obtained using computed tomography. Table 2 summarizes baseline data regarding aneurysmal characteristics and risk factors associated with the case and control groups.

\section{Univariate and Multivariate Analyses}

Univariate analysis revealed that the presence of hypertension, hyperlipidemia, diabetes mellitus, current cigarette smoking, alcohol consumption, the siesta habit, location of the largest aneurysm, large-sized aneurysms $(\geq 7 \mathrm{~mm})$, aneurysm shape (irregular), and AR were significantly associated with IA rupture $(P<0.05$, Table 3$)$. Results of a multivariate logistic regression

TABLE 1 | Patient characteristics.

\begin{tabular}{|c|c|c|c|}
\hline Characteristic & $\begin{array}{c}\text { Ruptured } \\
\text { aneurysms } \\
\text { (120 patients) }\end{array}$ & $\begin{array}{c}\text { Unruptured } \\
\text { aneurysms } \\
\text { (461 patients) }\end{array}$ & $\begin{array}{l}\text { Total patients } \\
\text { (581) }\end{array}$ \\
\hline Age, mean $\pm S D$, years & $54.0 \pm 11.2$ & $53.3 \pm 117.6$ & $53.4 \pm 10.9$ \\
\hline Female sex (\%) & $68(56.7)$ & 294 (63.8) & 362 (62.3) \\
\hline History of hypertension (\%) & 69 (57.5) & 207 (44.9) & $276(47.5)$ \\
\hline $\begin{array}{l}\text { History of } \\
\text { hyperlipidemia (\%) }\end{array}$ & $5(4.2)$ & $48(10.4)$ & $53(9.1)$ \\
\hline $\begin{array}{l}\text { History of diabetes } \\
\text { mellitus (\%) }\end{array}$ & $5(4.2)$ & $52(11.3)$ & $57(9.8)$ \\
\hline $\begin{array}{l}\text { History of ischemic } \\
\text { stroke }(\%)\end{array}$ & $11(9.2)$ & $37(8.0)$ & $48(8.3)$ \\
\hline History of heart disease (\%) & $7(5.8)$ & $19(4.1)$ & $26(4.5)$ \\
\hline Cigarette smoking, $n$ (\%) & & & 0.001 \\
\hline Never & $73(60.8)$ & $392(85.0)$ & $465(80.0)$ \\
\hline Past & 4 (3.3) & $18(3.9)$ & $22(3.8)$ \\
\hline Current $<20$ cigarettes/day & $11(9.2)$ & $17(3.7)$ & $28(4.8)$ \\
\hline Current $\geq 20$ cigarettes/day & $32(26.7)$ & $34(7.4)$ & 66 (11.4) \\
\hline Alcohol consumption, $n$ (\%) & $39(32.5)$ & $77(16.7)$ & $116(20.0)$ \\
\hline \multicolumn{4}{|l|}{ Body mass index $\left(\mathrm{kg} / \mathrm{m}^{2}\right)$} \\
\hline Mean $\pm S D$ & $25.0 \pm 4.0$ & $25.3 \pm 3.9$ & $25.3 \pm 3.9$ \\
\hline$<24(\%)$ & $53(44.2)$ & $181(39.3)$ & $234(40.3)$ \\
\hline 24-26 (\%) & $26(21.7)$ & 107 (23.2) & $133(22.9)$ \\
\hline$\geq 26(\%)$ & $41(34.2)$ & $173(37.5)$ & $214(36.8)$ \\
\hline \multicolumn{4}{|l|}{ Siesta, $h(\%)$} \\
\hline Never & $50(41.7)$ & $110(23.9)$ & $160(27.5)$ \\
\hline$<1(\%)$ & $21(17.5)$ & $83(18.0)$ & $104(17.9)$ \\
\hline$\geq 1(\%)$ & $49(40.8)$ & $268(58.1)$ & $317(68.8)$ \\
\hline \multicolumn{4}{|l|}{ Nocturnal sleep, $\boldsymbol{h}(\%)$} \\
\hline$<6(\%)$ & 39 (32.5) & $181(39.3)$ & $220(37.9)$ \\
\hline $6-7(\%)$ & $41(34.2)$ & $113(24.5)$ & $154(26.5)$ \\
\hline$\geq 7$ (\%) & 40 (33.3) & 167 (36.2) & 207 (35.6) \\
\hline $\begin{array}{l}\text { Multiple unruptured } \\
\text { aneurysms (\%) }\end{array}$ & $3(2.5)$ & $30(6.5)$ & $33(5.7)$ \\
\hline
\end{tabular}

model using a backward stepwise method are shown in Table 2. Adjusted ORs and 95\% CI for factors associated with IA rupture are shown in Table 3. Backward stepwise multivariate logistic regression analyses indicated that hypertension [odds ratio (OR) 1.68 , 95\% CI 1.03-2.73], hyperlipidemia (OR 0.25, 95\% CI $0.08-$ 0.72 ), current light smoker $<20$ cigarettes/day (OR 3.44, 95\% CI 1.18-10.10), current severe smoker $\geq 20$ cigarettes/day (OR 3.48, 95\% CI 1.63-7.47), siesta $\geq 1$ h (OR 0.49, 95\% CI 0.24-0.98), siesta $\geq 1$ h (OR $0.32,95 \%$ CI $0.19-0.57$ ), location of aneurysm on the anterior communicating artery (ACOM) (OR 16.27, 95\% CI 7.40-35.79), and internal carotid-posterior communicating artery (PCOM) (OR 11.21, 95\% CI 5.15-24.43) and diameter of largest aneurysm ( $\geq 7 \mathrm{~mm}$ ) (OR 2.19, 95\% CI 1.21-3.97) were significantly associated with risk of IA rupture $(P<0.05$, Table 3$)$.

\section{DISCUSSION}

In the present study, we found that the siesta habit is a new protective factor to assess the risk of IA rupture-the siesta habit can reduce the risk of aneurysm rupture. We also found that hypertension, hyperlipidemia, cigarette smoking, as well as the location, and diameter of the largest aneurysm were associated with the risk of rupture of IAs.

Several research studies demonstrate that hypertension is associated with an increased risk of aneurysmal rupture (15, 24, 25). In 2014, Tada et al. (15) described an animal model of IAs to evaluate the role of systemic hypertension and the renin-angiotensin system in aneurysmal rupture. These authors found that normalization of blood pressure after formation of

TABLE 2 | Aneurysmal characteristics

\begin{tabular}{cccc}
\hline Characteristic & $\begin{array}{c}\text { Ruptured } \\
\text { aneurysms } \\
(120)\end{array}$ & $\begin{array}{c}\text { Unruptured } \\
\text { aneurysms }\end{array}$ & $\begin{array}{c}\text { Total } \\
\text { aneurysms }\end{array}$ \\
& & $(514)$ & $(634)$
\end{tabular}

Location of largest aneurysm

(\%)

Internal carotid artery

Anterior cerebral artery

Middle cerebral artery

Anterior communicating artery

Internal carotid-posterior

communicating artery

Vertebral artery-posterior

inferior cerebellar artery and

vertebrobasilar junction

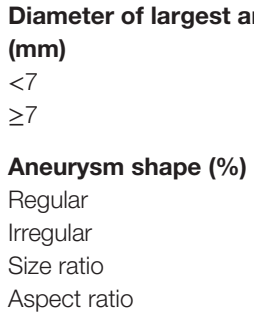

$\begin{array}{ccc}11(9.2) & 245(47.7) & 256(40.4) \\ 4(3.3) & 23(4.5) & 27(4.3) \\ 11(9.2) & 61(11.9) & 72(11.4) \\ 45(37.5) & 46(8.9) & 91(14.4) \\ 35(29.2) & 60(11.7) & 95(15.0) \\ 14(11.7) & 79(15.4) & 93(14.7)\end{array}$

Flow angles in degrees (\%)

$<90$

$\geq 90$

$\begin{array}{lcc}79(65.8) & 405(78.8) & 484(76.3) \\ 41(34.2) & 109(21.2) & 150(23.7) \\ & & \\ 31(25.8) & 213(41.4) & 244(38.5) \\ 89(74.2) & 301(58.6) & 390(61.5) \\ 2.0 \pm 1.6 & 2.0 \pm 1.7 & 2.0 \pm 1.6 \\ 1.5 \pm 0.8 & 1.4 \pm 0.9 & 17.0 \pm 2.0 \\ & & \\ 57(47.5) & 201(39.1) & 258(40.7) \\ 63(52.5) & 313(60.9) & 376(59.3)\end{array}$


TABLE 3 | Univariate and multivariate regression analysis for rupture of intracranial aneurysms.

\begin{tabular}{|c|c|c|}
\hline Characteristic & $\begin{array}{l}\text { Univariate analysis } \\
\text { hazard ratio }(95 \% \mathrm{Cl})\end{array}$ & $\begin{array}{l}\text { Multivariate } \\
\text { analysis hazard } \\
\text { ratio }(95 \% \mathrm{Cl})\end{array}$ \\
\hline Age & $1.00(0.98-1.02)$ & - \\
\hline Female sex & $0.74(0.50-1.12)$ & - \\
\hline History of hypertension & $1.67(1.11-2.50)$ & 1.68 (1.03-2.73) \\
\hline History of hyperlipidemia & $0.37(0.15-0.96)$ & $0.25(0.08-0.72)$ \\
\hline History of diabetes mellitus & $0.34(0.13-0.88)$ & $0.42(0.17-1.06)$ \\
\hline History of ischemic stroke & $1.16(0.57-2.34)$ & - \\
\hline History of heart disease & $1.44(0.59-3.51)$ & - \\
\hline \multicolumn{3}{|l|}{ Cigarette smoking, $n$} \\
\hline Never & Reference & Reference \\
\hline Past & $1.06(0.35-3.16)$ & $0.83(0.22-3.24)$ \\
\hline Current $<20$ cigarettes/day & $3.21(1.47-7.02)$ & $3.44(1.18-10.10)$ \\
\hline Current $\geq 20$ cigarettes/day & $5.23(3.07-8.92)$ & $3.48(1.63-7.47)$ \\
\hline Alcohol consumption & $2.40(1.53-3.78)$ & $1.49(0.73-3.04)$ \\
\hline \multicolumn{3}{|l|}{ Body mass index $\left(\mathrm{kg} / \mathrm{m}^{2}\right)$} \\
\hline Mean \pm SD & $0.98(0.92-1.03)$ & - \\
\hline$<24$ & Reference & \\
\hline $24-26$ & $0.84(0.50-1.42)$ & - \\
\hline$\geq 26$ & $0.87(0.56-1.35)$ & - \\
\hline \multicolumn{3}{|l|}{ Siesta, $h$} \\
\hline Never & Reference & Reference \\
\hline$<1$ & $0.56(0.31-0.99)$ & $0.49(0.24-0.98)$ \\
\hline$\geq 1$ & $0.40(0.26-0.63)$ & $0.32(0.19-0.57)$ \\
\hline \multicolumn{3}{|l|}{ Nocturnal sleep, $\boldsymbol{h}$} \\
\hline$<6$ & Reference & \\
\hline $6-7$ & $1.60(0.97-2.63)$ & - \\
\hline$\geq 7$ & $1.08(0.67-1.76)$ & - \\
\hline Multiple unruptured aneurysms & $0.37(0.11-1.23)$ & - \\
\hline \multicolumn{3}{|l|}{ Location of largest aneurysm } \\
\hline Internal carotid artery & Reference & Reference \\
\hline Anterior cerebral artery & $3.87(1.14-13.14)$ & $3.49(0.95-12.89)$ \\
\hline Middle cerebral artery & $4.02(1.67-9.70)$ & $6.44(2.70-15.37)$ \\
\hline Anterior communicating artery & $21.79(10.49-45.24)$ & $16.27(7.40-35.79)$ \\
\hline $\begin{array}{l}\text { Internal carotid-posterior } \\
\text { communicating artery }\end{array}$ & $12.99(6.24-27.07)$ & $11.21(5.15-24.43)$ \\
\hline $\begin{array}{l}\text { Vertebral artery-posterior } \\
\text { inferior cerebellar artery and } \\
\text { vertebrobasilar junction }\end{array}$ & $3.95(1.72-9.05)$ & $3.07(1.27-7.41)$ \\
\hline $\begin{array}{l}\text { Diameter of largest aneurysm } \\
(\geq 7 \mathrm{~mm})\end{array}$ & $1.93(1.25-2.97)$ & $2.19(1.21-3.97)$ \\
\hline Aneurysm shape (irregular) & $2.03(1.30-3.17)$ & $1.56(0.93-2.60)$ \\
\hline Size ratio & $1.01(0.90-1.14)$ & - \\
\hline Aspect ratio & $1.23(1.00-1.52)$ & $1.02(0.75-1.37)$ \\
\hline Flow angles $\left(\geq 90^{\circ}\right)$ & $0.71(0.48-1.06)$ & - \\
\hline
\end{tabular}

an aneurysm prevented aneurysmal rupture in mice and that inhibition of the local renin-angiotensin system could also prevent aneurysmal rupture independent of the reduction of blood pressure. Hypertension could produce multiple effects as follows: (1) the wall of a formed aneurysm may be weakened due to a direct increase in mechanical stresses, (2) systemic hypertension causes activation of the local renin-angiotensin system leading to vascular inflammation and remodeling and thereby contributes to aneurysmal rupture (26), (3) reportedly, certain polymorphisms in genes related to the renin-angiotensin system are associated with aneurysm rupture (15). Starke et al. (27) found that the tumor necrosis factor (TNF- $\alpha$ ) plays a majoir role in the formation and rupture of aneurysms and that hypertension in conjunction with hemodynamic stress in rats in vivo increases the expression of TNF- $\alpha$. Therefore, hypertension may directly or indirectly contribute to aneurysmal rupture. Additionally, our study showed that hypertension was an independent risk factor associated with a risk of IA rupture with an OR 1.68 and 95\% CI $1.03-2.73$.

Siesta or a noon nap (wu jiao in Chinese) is a common practice prevalent in China, Mediterranean countries, and in Latin America and is considered part of a healthy lifestyle in Chinese culture (28). Most old people in China take a habitual siesta for its health benefits (29). Cai et al. (16) found that a siesta was an independent risk factor associated with a lower prevalence of hypertension in older adults. A recent study revealed that a daily nap may accelerate cardiovascular recovery following mental stresses and additionally provide cardiovascular benefits and significantly lower mean arterial pressure were found during the recovery phase of the stress reactivity task among participants who received more than $45 \mathrm{~min}$ of daytime sleep (17). These studies demonstrate that it is reasonable to deduce that a siesta directly affects blood pressure and hypertension through the mechanism of cardiovascular recovery. A study found that adipocyte fatty acid-binding protein ( $\mathrm{aP} 2$ or FABP4) is an adipokine known to be associated with an elevated blood pressure (30). Serum concentrations of adipocyte fatty acid-binding protein were lower in those taking a nap compared to subjects who could be classified as non-siesta subjects (16). These studies suggest that adipocyte fatty acid-binding protein probably has some role in the association between siesta and hypertension. However, to date, a relationship between the siesta habit and IA rupture has not been reported. In our study, we found that a siesta is a protective factor to help assess the risk of IA rupture and that the siesta habit can reduce the risk of aneurysm rupture. The OR for siesta $<1$ h was $0.49(0.24-0.98)$, siesta $\geq 1$ h was $0.32,95 \%$ CI $0.19-0.57$. A siesta may indirectly reduce the risk of aneurysmal rupture by lowering blood pressure. Further studies would be needed to understand the mechanisms by which a siesta affects the risk of aneurysm rupture.

Although the etiology is unclear, hypercholesterolemia may be associated with a reduced risk of $\operatorname{SAH}(9,19)$. We found that hypercholesterolemia was a protective factor for IA rupture with an OR of $0.25,95 \%$ CI $0.08-0.72$. Cigarette smoking was an important risk factor associated with the risk of IA rupture. Many studies also report that smoking is an independent risk factor associated with aneurysmal rupture (20, 31-36). Longterm smoking affects vascular homeostasis and structural integrity of the vessel wall. Additionally, a deficiency of alpha 1 -antitrypsin or one of the other protease inhibitors could cause degradation of the arterial wall due to an imbalance between proteolytic enzymes and their inhibitors, thereby predisposing the arterial wall to dissection or aneurysm formation (37-39). Our study showed that current smokers who smoked $>20$ cigarettes per day demonstrated a higher incidence of ruptured IA. Previous studies have reported that IAs located along the $\operatorname{ACOM}(9,40)$ or PCOM $(6,9,41)$ were significantly associated with the risk of rupture. In our study, ACOM (OR 16.27, 95\% CI 7.40-35.79) and PCOM (OR 11.21, 95\% CI 5.15-24.43) showed the highest incidence of rupture compared to those in other 
locations. Our study results matched those of previous studies, which demonstrate that aneurysm diameter $\geq 7 \mathrm{~mm}$ independently predicted subsequent aneurysm rupture $(40,42)$. The OR for aneurysmal diameter of the largest aneurysm $(\geq 7 \mathrm{~mm})$ was 2.19, 95\% CI 1.21-3.97.

Factors that reportedly increase the risk of aneurysm rupture are the patient's age, sex, multiple unruptured aneurysms, shape, SR, AR, and flow angles (10,43-51), which may be independent risk factors for aneurysm rupture. However, in this study, these risk factors were non-significant.

\section{Limitations}

The limitations of our study are: (1) our data did not include information regarding the quality of siesta and sleep such as initial insomnia and sleep fragmentation. It cannot be denied that the quality of a siesta and sleep may affect the association between siesta and aneurysm rupture, (2) ours was a single-center retrospective study with the possibility of a selection and referral bias. Our findings are entirely based on assessment of a Chinese population, (3) the effect of aneurysm rupture and subsequent hemorrhage on aneurysm geometry was not considered, although several studies suggest that rupture does not significantly alter aneurysm morphology $(23,52,53),(4)$ previous studies suggested an annual risk of rupture of $0.34-1.3 \%(40,54-56)$ among unruptured aneurysms, so there is inevitably unequal cohort sizes of ruptured and unruptured IAs, which might have influenced our results.

\section{REFERENCES}

1. Vlak MH, Rinkel GJ, Greebe P, Jg VDB, Algra A. Trigger factors and their attributable risk for rupture of intracranial aneurysms: a case-crossover study. Stroke (2011) 42:1878. doi:10.1161/STROKEAHA.110.606558

2. Vlak MH, Algra A, Brandenburg R, Rinkel GJ. Prevalence of unruptured intracranial aneurysms, with emphasis on sex, age, comorbidity, country, and time period: a systematic review and meta-analysis. Lancet Neurol (2011) 10:626-36. doi:10.1016/S1474-4422(11)70109-0

3. Lindgren AE, Koivisto T, Björkman J, von Und Zu Fraunberg M, Helin K, Jääskeläinen JE, et al. Irregular shape of intracranial aneurysm indicates rupture risk irrespective of size in a population-based cohort. Stroke (2016) 47:1219-26. doi:10.1161/STROKEAHA.115.012404

4. Rinkel GJ, Djibuti M, Algra A, van Gijn J. Prevalence and risk of rupture of intracranial aneurysms: a systematic review. Stroke (1998) 29:251-6. doi:10.1161/01.STR.29.1.251

5. Gabriel RA, Kim H, Sidney S, McCulloch CE, Singh V, Johnston SC, et al. Ten-year detection rate of brain arteriovenous malformations in a large, multiethnic, defined population. Stroke (2010) 41:21-6. doi:10.1161/ STROKEAHA.109.566018

6. Kang H, Ji W, Qian Z, Li Y, Jiang C, Wu Z, et al. Aneurysm characteristics associated with the rupture risk of intracranial aneurysms: a self-controlled study. PLoS One (2015) 10:e0142330. doi:10.1371/journal.pone.0142330

7. Steiner T, Juvela S, Unterberg A, Jung C, Forsting M, Rinkel G, et al. European stroke organization guidelines for the management of intracranial aneurysms and subarachnoid haemorrhage. Cerebrovasc Dis (2013) 35:93-112. doi:10.1159/000346087

8. Vlak MH, Rinkel GJ, Greebe P, Algra A. Risk of rupture of an intracranial aneurysm based on patient characteristics: a case-control study. Stroke (2013) 44:1256-9. doi:10.1161/STROKEAHA.111.000679

9. UCAS Japan Investigators, Morita A, Kirino T, Hashi K, Aoki N, Fukuhara S, et al. The natural course of unruptured cerebral aneurysms in a Japanese cohort. $N$ Engl J Med (2012) 366:2474-82. doi:10.1056/ NEJMoa1113260

10. Backes D, Vergouwen MD, Velthuis BK, van der Schaaf IC, Bor AS, Algra A, et al. Difference in aneurysm characteristics between ruptured

\section{CONCLUSION}

Siesta is a new protective factor for assessment of the risk of IA rupture, and we could demonstrate that the siesta habit can reduce the risk of aneurysm rupture. We also found that hypertension, hyperlipidemia, cigarette smoking, location, and diameter of the largest aneurysm were associated with the risk of rupture of IAs.

\section{AUTHOR CONTRIBUTIONS}

Conceived and designed the experiments: AL, HZ. Performed the experiments: HK, XF. Analyzed the data: HK, XF, BZ. Contributed to reagents/materials/analysis tools: $\mathrm{EG}, \mathrm{ZQ}, \mathrm{LW}, \mathrm{PL}, \mathrm{XW}, \mathrm{WX}$, YL, and CJ. Wrote the paper: HK, XF. Revised the manuscript: ZW.

\section{FUNDING}

This work was supported by the Natural Science Foundation of Beijing, China (No.7142032), and Specific Research Projects for Capital Health Development (2014-3-2044).

\section{SUPPLEMENTARY MATERIAL}

The Supplementary Material for this article can be found online at http://journal.frontiersin.org/article/10.3389/fneur.2017.00451/ full\#supplementary-material.

and unruptured aneurysms in patients with multiple intracranial aneurysms. Stroke (2014) 45:1299-303. doi:10.1161/STROKEAHA.113. 004421

11. Mensing LA, Rinkel GJ, Vlak MH, van der Schaaf IC, Ruigrok YM. Difference in aneurysm characteristics between patients with familial and sporadic aneurysmal subarachnoid haemorrhage. PLoS One (2016) 11:e0154281. doi:10.1371/journal.pone. 0154281

12. Brinjikji W, Lingineni RK, Gu CN, Lanzino G, Cloft HJ, Ulsh L, et al. Smoking is not associated with recurrence and retreatment of intracranial aneurysms after endovascular coiling. J Neurosurg (2014) 122:95-100. doi:10.3171/2014.10.JNS141035

13. Rahman M, Smietana J, Hauck E, Hoh B, Hopkins N, Siddiqui A, et al. Size ratio correlates with intracranial aneurysm rupture status: a prospective study. Stroke (2010) 41:916-20. doi:10.1161/STROKEAHA.109.574244

14. Connolly ES Jr, Rabinstein AA, Carhuapoma JR, Derdeyn CP, Dion J, Higashida RT, et al. Guidelines for the management of aneurysmal subarachnoid hemorrhage: a guideline for healthcare professionals from the American Heart Association/American Stroke Association. Stroke (2012) 43:1711-37. doi:10.1161/STR.0b013e3182587839

15. Tada Y, Wada K, Shimada K, Makino H, Liang EI, Murakami S, et al. Roles of hypertension in the rupture of intracranial aneurysms. Stroke (2014) 45:579-86. doi:10.1161/STROKEAHA.113.003072

16. Cai M, Huang Y, Sun X, He Y, Sun C. Siesta is associated with reduced systolic blood pressure level and decreased prevalence of hypertension in older adults. J Hum Hypertens (2016) 30:216-8. doi:10.1038/jhh.2015.70

17. Brindle RC, Conklin SM. Daytime sleep accelerates cardiovascular recovery after psychological stress. Int J Behav Med (2012) 19:111-4. doi:10.1007/ s12529-011-9150-0

18. Stang A, Dragano N, Poole C, Moebus S, Möhlenkamp S, Schmermund A, et al. Daily siesta, cardiovascular risk factors, and measures of subclinical atherosclerosis: results of the Heinz Nixdorf recall study. Sleep (2007) 30(9):1111-9. doi:10.1093/sleep/30.9.1111

19. Feigin VL, Rinkel GJ, Lawes CM, Algra A, Bennett DA, van Gijn J, et al. Risk factors for subarachnoid hemorrhage: an updated systematic review of epidemiological studies. Stroke (2005) 36:2773-80. doi:10.1161/01. STR.0000190838.02954.e8 
20. Vlak MH, Rinkel GJ, Greebe P, Algra A. Independent risk factors for intracranial aneurysms and their joint effect: a case-control study. Stroke (2013) 44:984-7. doi:10.1161/STROKEAHA.111.000329

21. Ujiie $\mathrm{H}$, Tachibana $\mathrm{H}$, Hiramatsu $\mathrm{O}$, Hazel AL, Matsumoto $\mathrm{T}$, Ogasawara Y, et al. Effects of size and shape (aspect ratio) on the hemodynamics of saccular aneurysms: a possible index for surgical treatment of intracranial aneurysms. J Neurosurg (1999) 45:119-129; discussion 129-30. doi:10.1097/ 00006123-199907000-00028

22. Ujiie H, Tamano $Y$, Sasaki K, Hori T. Is the aspect ratio a reliable index for predicting the rupture of a saccular aneurysm? J Neurosurg (2001) 48:495-502; discussion 502-493. doi:10.1097/00006123-200103000-00007

23. Dhar S, Tremmel M, Mocco J, Kim M, Yamamoto J, Siddiqui AH, et al. Morphology parameters for intracranial aneurysm rupture risk assessment. J Neurosurg (2008) 63:185-196; discussion 196-187. doi:10.1227/01. NEU.0000316847.64140.81

24. Liakos CI, Grassos CA, Babalis DK; European Society of Hypertension; European Society of Cardiology. 2013 ESH/ESC guidelines for the management of arterial hypertension: what has changed in daily clinical practice? High Blood Press Cardiovasc Prev (2015) 22:43-53. doi:10.1007/s40292-014-0071-2

25. Najafipour H, Nasri HR, Afshari M, Moazenzadeh M, Shokoohi M, Foroud A, et al. Hypertension: diagnosis, control status and its predictors in general population aged between 15 and 75 years: a community-based study in southeastern Iran. Int J Public Health (2014) 59:999-1009. doi:10.1007/ s00038-014-0602-6

26. Muller M, van den Beld AW, Bots ML, Grobbee DE, Lamberts SW, van der Schouw YT. Endogenous sex hormones and progression of carotid atherosclerosis in elderly men. Circulation (2004) 109:2074-9. doi:10.1161/01. CIR.0000125854.51637.06

27. Starke RM, Chalouhi N, Jabbour PM, Tjoumakaris SI, Gonzalez LF, Rosenwasser RH, et al. Critical role of TNF-alpha in cerebral aneurysm formation and progression to rupture. J Neuroinflammation (2014) 11:77. doi:10.1186/1742-2094-11-77

28. Naska A, Oikonomou E, Trichopoulou A, Psaltopoulou T, Trichopoulos D. Siesta in healthy adults and coronary mortality in the general population. Arch Intern Med (2007) 167:296-301. doi:10.1001/archinte.167.3.296

29. Lucassen EA. To nap or not to nap: is the Wu Jiao a healthy habit? Sleep Med (2013) 14:929. doi:10.1016/j.sleep.2013.05.010

30. Xu A, Wang Y, Xu JY, Stejskal D, Tam S, Zhang J, et al. Adipocyte fatty acid-binding protein is a plasma biomarker closely associated with obesity and metabolic syndrome. Clin Chem (2006) 52:405-13. doi:10.1373/ clinchem.2005.062463

31. Jiang H, Weng YX, Zhu Y, Shen J, Pan JW, Zhan RY. Patient and aneurysm characteristics associated with rupture risk of multiple intracranial aneurysms in the anterior circulation system. Acta Neurochir (2016) 158:1367-75. doi:10.1007/s00701-016-2826-0

32. Brown RD Jr, Broderick JP. Unruptured intracranial aneurysms: epidemiology, natural history, management options, and familial screening. Lancet Neurol (2014) 13:393-404. doi:10.1016/S1474-4422(14)70015-8

33. Ghosh S, Dey S, Tjoumakaris S, Gonzalez F, Rosenwasser R, Pascal J, et al. Association of morphologic and demographic features of intracranial aneurysms with their rupture: a retrospective analysis. Acta Neurochir Suppl (2013) 115:275-8. doi:10.1007/978-3-7091-1192-5_48

34. Gu YX, Chen XC, Song DL, Leng B, Zhao F. Risk factors for intracranial aneurysm in a Chinese ethnic population. Chin Med Sci J (2006) 119:1359-64.

35. Inagawa T. Risk factors for the formation and rupture of intracranial saccular aneurysms in Shimane, Japan. World Neurosurg (2010) 73:155-164; discussion e123. doi:10.1016/j.surneu.2009.03.007

36. Marbacher S, Schlappi JA, Fung C, Husler J, Beck J, Raabe A. Do statins reduce the risk of aneurysm development? A case-control study. J Neurosurg (2012) 116:638-42. doi:10.3171/2011.10.JNS11153

37. Peters DG, Kassam A, St Jean PL, Yonas H, Ferrell RE. Functional polymorphism in the matrix metalloproteinase-9 promoter as a potential risk factor for intracranial aneurysm. Stroke (1999) 30:2612-6. doi:10.1161/01.STR.30.12.2612

38. Schievink WI, Prakash UB, Piepgras DG, Mokri B. Alpha 1-antitrypsin deficiency in intracranial aneurysms and cervical artery dissection. Lancet (1994) 343:452-3. doi:10.1016/S0140-6736(94)92693-X

39. St Jean P, Hart B, Webster M, Steed D, Adamson J, Powell J, et al. Alpha-1antitrypsin deficiency in aneurysmal disease. Hum Hered (1996) 46:92-7. doi:10.1159/000154333
40. Juvela S, Poussa K, Lehto H, Porras M. Natural history of unruptured intracranial aneurysms: a long-term follow-up study. Stroke (2013) 44:2414-21. doi:10.1161/STROKEAHA.113.001838

41. Wiebers DO, Whisnant JP, Huston J III, Meissner I, Brown RD Jr, Piepgras DG, et al. Unruptured intracranial aneurysms: natural history, clinical outcome, and risks of surgical and endovascular treatment. Lancet (2003) 362:103-10. doi:10.1016/S0140-6736(03)13860-3

42. Korja M, Lehto $\mathrm{H}$, Juvela $\mathrm{S}$. Lifelong rupture risk of intracranial aneurysms depends on risk factors: a prospective Finnish cohort study. Stroke (2014) 45:1958-63. doi:10.1161/STROKEAHA.114.005318

43. Tominari S, Morita A, Ishibashi T, Yamazaki T, Takao H, Murayama $\mathrm{Y}$, et al. Prediction model for three-year rupture risk of unruptured cerebral aneurysms in Japanese patients. Ann Neurol (2015) 77:1050-9. doi:10.1002/ ana. 24400

44. Backes D, Vergouwen MD, Tiel Groenestege AT, Bor AS, Velthuis BK, Greving JP, et al. Phases score for prediction of intracranial aneurysm growth Stroke (2015) 46:1221-6. doi:10.1161/STROKEAHA.114.008198

45. Bor AS, Tiel Groenestege AT, terBrugge KG, Agid R, Velthuis BK, Rinkel GJ, et al. Clinical, radiological, and flow-related risk factors for growth of untreated, unruptured intracranial aneurysms. Stroke (2015) 46:42-8. doi:10.1161/STROKEAHA.114.005963

46. Matsumoto K, Oshino S, Sasaki M, Tsuruzono K, Taketsuna S, Yoshimine T. Incidence of growth and rupture of unruptured intracranial aneurysms followed by serial MRA. Acta Neurochir (2013) 155:211-6. doi:10.1007/s00701-012-1566-z

47. Amenta PS, Yadla S, Campbell PG, Maltenfort MG, Dey S, Ghosh S, et al. Analysis of nonmodifiable risk factors for intracranial aneurysm rupture in a large, retrospective cohort. J Neurosurg (2012) 70:693-99; discussion 699-701. doi:10.1227/NEU.0b013e3182354d68

48. Lin N, Ho A, Gross BA, Pieper S, Frerichs KU, Day AL, etal. Differences in simple morphological variables in ruptured and unruptured middle cerebral artery aneurysms. J Neurosurg (2012) 117:913-9. doi:10.3171/2012.7.JNS111766

49. Kashiwazaki D, Kuroda S. Size ratio can highly predict rupture risk in intracranial small $(<5 \mathrm{~mm})$ aneurysms. Stroke (2013) 44:2169-73. doi:10.1161/ STROKEAHA.113.001138

50. Matsukawa H, Uemura A, Fujii M, Kamo M, Takahashi O, Sumiyoshi S. Morphological and clinical risk factors for the rupture of anterior communicating artery aneurysms. J Neurosurg (2013) 118:978-83. doi:10.3171/2012.11. JNS121210

51. Baharoglu MI, Schirmer CM, Hoit DA, Gao BL, Malek AM. Aneurysm inflow-angle as a discriminant for rupture in sidewall cerebral aneurysms. Stroke (2010) 41:1423-30. doi:10.1161/STROKEAHA.109.570770

52. Raghavan ML, Ma B, Harbaugh RE. Quantified aneurysm shape and rupture risk. J Neurosurg (2005) 102:355-62. doi:10.3171/jns.2005.102. 2.0355

53. Ujiie H, Tamano Y, Sasaki K, Hori T. Is the aspect ratio a reliable index for predicting the rupture of a saccular aneurysm? J Neurosurg (2001) 48:495-503. doi:10.1097/00006123-200103000-00007

54. Rinaldo L, Shepherd DL, Murphy ME, Vine RL, Brown RD Jr, Rabinstein AA, et al. Natural history of untreated unruptured intracranial aneurysms in the elderly. J Neurosurg Sci (2016) 119(16):1359-64.

55. Sonobe M, Yamazaki TM, Kikuchi H. Small unruptured intracranial aneurysm verification study: SUAVe study, Japan. Stroke (2010) 41(9):1969. doi:10.1161/ STROKEAHA.110.585059

56. Juvela S, Porras M, Poussa K. Natural history of unruptured intracranial aneurysms: probability of and risk factors for aneurysm rupture. J Neurosurg (2008) 108(5):1052-60. doi:10.3171/JNS/2008/108/5/1052

Conflict of Interest Statement: The authors declare that the research was conducted in the absence of any commercial or financial relationships that could be construed as a potential conflict of interest.

Copyright $\odot 2017$ Kang, Feng, Zhang, Guo, Wang, Qian, Liu, Wen, Xu, Li, Jiang, $W u$, Zhang and Liu. This is an open-access article distributed under the terms of the Creative Commons Attribution License (CC BY). The use, distribution or reproduction in other forums is permitted, provided the original author(s) or licensor are credited and that the original publication in this journal is cited, in accordance with accepted academic practice. No use, distribution or reproduction is permitted which does not comply with these terms. 